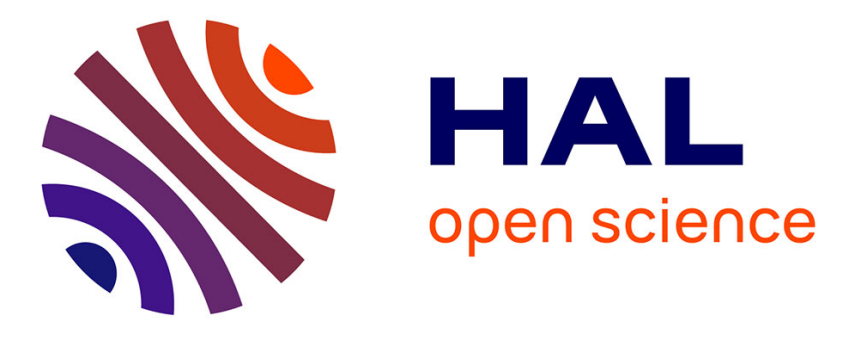

\title{
Rapid directivity detection by azimuthal amplitude spectra inversion
}

Simone Cesca, Sebastian Heimann, Torsten Dahm

\section{To cite this version:}

Simone Cesca, Sebastian Heimann, Torsten Dahm. Rapid directivity detection by azimuthal amplitude spectra inversion. Journal of Seismology, 2010, 15 (1), pp.147-164. 10.1007/s10950-010-9217-4 . hal00642936

\section{HAL Id: hal-00642936 \\ https://hal.science/hal-00642936}

Submitted on 20 Nov 2011

HAL is a multi-disciplinary open access archive for the deposit and dissemination of scientific research documents, whether they are published or not. The documents may come from teaching and research institutions in France or abroad, or from public or private research centers.
L'archive ouverte pluridisciplinaire HAL, est destinée au dépôt et à la diffusion de documents scientifiques de niveau recherche, publiés ou non, émanant des établissements d'enseignement et de recherche français ou étrangers, des laboratoires publics ou privés. 


\section{Rapid directivity detection by azimuthal amplitude spectra inversion}

\author{
Simone Cesca • Sebastian Heimann • \\ Torsten Dahm
}

Received: 24 February 2010 / Accepted: 4 November 2010

(C) Springer Science+Business Media B.V. 2010

1 Abstract An early detection of the presence of 2 rupture directivity plays a major role in the correct 3 estimation of ground motions and risks associated 4 to the earthquake occurrence. We present here 5 a simple method for a fast detection of rupture 6 directivity, which may be additionally used to 7 discriminate fault and auxiliary planes and have 8 first estimations of important kinematic source 9 parameters, such as rupture length and rupture 10 time. Our method is based on the inversion of 11 amplitude spectra from $\mathrm{P}$-wave seismograms to 12 derive the apparent duration at each station and 13 on the successive modelling of its azimuthal be14 haviour. Synthetic waveforms are built assuming a 15 spatial point source approximation, and the finite 16 apparent duration of the spatial point source is 17 interpreted in terms of rupture directivity. Since 18 synthetic seismograms for a point source are cal19 culated very quickly, the presence of directivity 20 may be detected within few seconds, once a focal 21 mechanism has been derived. The method is here 22 first tested using synthetic datasets, both for lin23 ear and planar sources, and then successfully ap24 plied to recent $\mathrm{Mw}$ 6.2-6.8 shallow earthquakes in 25 Peloponnese, Greece. The method is suitable for

S. Cesca $(\varangle) \cdot$ S. Heimann · T. Dahm Institut für Geophysik, Universität Hamburg, Bundesstrasse 55, 20146 Hamburg, Germany e-mail: simone.cesca@zmaw.de automated application and may be used to im- 26 prove kinematic waveform modelling approaches. 27

Keywords Directivity • Earthquake source • 29 Kinematic model $\cdot$ Amplitude spectra 30

\section{Introduction}

Tectonically driven shallow earthquake sources 32 are generally explained by means of shear cracks 33 occurring along a limited, almost planar region, 34 we refer as the focal region. A point source repre- 35 sentation is a common first approximation, which 36 is valid when treating far-field low frequency seis- 37 mic waveform, using wavelengths larger than the 38 rupture size. Higher frequencies seismograms and 39 spectra contain information which can be related 40 to the finiteness of the rupture process and thus 41 can be used to determine parameters describing 42 the finite source. Size and shape of the rupture 43 area, rupture velocity and preferential rupture 44 directions, an effect known as rupture directivity, 45 are some of the parameters which can be retrieved 46 by the analysis of high-frequency waveforms. In 47 particular, we are interested here in discussing the 48 problem of early detection of rupture directiv- 49 ity, distinguishing between a prominent or partial 50 unilateral rupture (a case which will be further 51 referred as asymmetric bilateral rupture), and a 52 
53 bilateral one, with rupture nucleating at the centre 54 of the rupture area and propagating toward its 55 edges. The azimuthal dependency of amplitudes 56 and durations of different seismic phases is a first 57 indicator of directivity effects and is consequence 58 of the characteristics of the finite rupture process 59 along the fault plane, specifically the main di60 rection and speed of the rupture front propaga61 tion. Directivity has been often observed and has 62 been modelled for several earthquakes in the past, 63 with several studies treating specific earthquakes 64 or limited datasets (e. g., McGuire et al. 2002; 65 Warren and Shearer 2006; Caldeira et al. 2009). A 66 quick detection of directivity effects is important 67 towards a correct estimation of ground motions, 68 stress field perturbations and tsunamogenic risks 69 and consequently to mitigate earthquake effects. 70 These considerations provide important reasons 71 to further investigate and develop specific tools 72 for stable, rapid and automated directivity de73 tection, which can be used within early warning 74 systems.

75 Several methods have been applied in the past 76 to detect and classify earthquake source direc77 tivity. A common approach is the identification 78 of predominant unilateral ruptures from the time 79 duration and spectral analysis of body wave pulses 80 (e.g. Boore and Joyner 1978; Beck et al. 1995; 81 Warren and Shearer 2006; Caldeira et al. 2009). 82 Pulse lengths at different stations are interpreted 83 in terms of the apparent duration of the source 84 time function (STF), and their variation in depen85 dence on azimuth and incidence angle is inter86 preted to detect directivity: similarly to a Doppler 87 effect in classical physics, shorter STFs would in88 dicate a rupture propagating towards the consid89 ered station, while longer pulses indicate a rupture 90 propagation in the opposite direction. Directiv91 ity effects may also be revealed based on the 92 analysis of surface waves at different azimuths 93 (Ben-Menahem 1961; Pro et al. 2007). Whereas 94 time domain methods remain more common, a 95 significant contribution within this type of inver96 sion methods was provided by the spectral ap97 proach discussed in Warren and Shearer (2006). 98 This method is based on the spectral estimation 99 of the pulse broadening and accounts for the az100 imuthal and incidence angle dependencies; it is 101 well suited for the analysis of intermediate and deep focus earthquakes and was successfully ap- 102 plied to several events. The main limits of this 103 class of methods are related to the fact that wave 104 propagation and the superposition of different 105 seismic phases are not accounted, since wave 106 propagation effects between source and receiver 107 (Green's functions) are limited to the estimation 108 of the incidence angle of given seismic phases. 109 Another possible limitation is the requirement of 110 several stations with good azimuthal coverage in 111 order to ensure reliable results. A second range 112 of applications, which on the contrary accounts 113 precisely for the effects of the earth's model on 114 the observed waveforms, is based on empirical 115 Green's functions technique (Hartzell 1978; Li 116 and Toksöz 1993; Velasco et al. 1994; Cassidy 117 1995; Müller 1985; Velasco et al. 2004; Vallée 118 2007). In this case, an aftershock with common 119 hypocenter and focal mechanism of the studied 120 event can be used to remove path effects, and iso- 121 late finite source apparent durations at different 122 stations. Evidently, the application of these tech- 123 niques is strongly limited by the availability of 124 a proper aftershock. Brüstle and Müller (1987), 125 and Imanishi and Takeo (2002) have investigated 126 the adoption of master-event techniques to detect 127 directivity: the identification of stopping phases 128 (Madariaga 1977, 1983; Bernard and Madariaga 129 1984; Spudich and Frazer 1984) at different sta- 130 tions was used there to determine the main di- 131 rection of rupture propagation, besides other 132 source properties. Stopping phases identification 133 (Imanishi and Takeo 1998, 2002) typically re- 134 quires a careful waveform analysis, which may be 135 hardly implemented within automated routines. 136 A third group of techniques are based on com- 137 plete kinematic waveform inversion, with the aim 138 of retrieving a most detailed image of the finite 139 rupture process, not limited to the identification 140 of directivity. The range of methods and appli- 141 cations is very wide, including higher order mo- 142 ment tensor analysis (Dahm and Krüger 1999; 143 McGuire et al. 2001, 2002), detailed slip map 144 approaches (e.g. Olson and Apsel 1982; Hartzell 145 and Helmberger 1982; Hartzell and Heaton 1983; 146 Beroza and Spudich 1988), and inversion meth- 147 ods adopting constrained and simplified kinematic 148 models (Dreger and Kaverina 2000; Vallée and 149 Bouchon 2004; Gallovic et al. 2009; Cesca et al. 150 
151 2010). All these methods have a significant poten152 tial for a stable determination of directivity but 153 their adoption towards its very fast detection is 154 limited, often requiring time consuming computa155 tion of synthetic seismograms for several extended 156 source models. Methods developed by Dreger and 157 Kaverina (2000) and following Cesca et al. (2010) 158 have shown a good performance and have been 159 tested for near real-time applications, but they are 160 still based on extended source representations and 161 thus require heavier computations with respect to 162 our method. Finally, recent results by Zahradnik 163 et al. (2008) showed the possibility of discrimi164 nating the true fault plane on the base of spatial 165 offsets between epicentre and centroid locations. 166 However, the method has been currently applied 167 only to a limited number of earthquakes, with 168 variable results, and the determination of directiv169 ity may be beyond its possibilities, for example for 170 symmetric bilateral ruptures.

171 We present here a simple alternative method to 172 quickly detect directivity for shallow earthquakes 173 and discuss it with the aid of a set of applica174 tions, including both synthetic datasets and obser175 vations from recent earthquakes in Greece. Our 176 method is based on a point source representation, 177 which drastically reduces computational require178 ments and makes it feasible for early detection. 179 Directivity is detected on the basis of a frequency 180 domain inversion of the apparent duration at 181 each station and the further interpretation of its 182 azimuthal variation. Main strength points of the 183 proposed method include the adoption of a com184 mon dataset and modelling tools for focal mech185 anism and directivity determination, the inclusion 186 of Green's functions accounting for wave propa187 gation through the chosen earth models without 188 needing specific aftershocks, and the simplicity 189 and quickness of the inversion process.

\section{Directivity and amplitude spectra inversion}

191 We make here use of the recently developed 192 Kiwi tools (Heimann 2010; Cesca et al. 2010; $193 \mathrm{http}: / /$ kinherd.org), which provide a flexible in194 strument to generate synthetic seismograms for 195 point and extended sources and to invert different 196 earthquake source parameters, allowing the se- lection of different waveform tapers, frequency 197 filters, inversion domains and misfit functions. 198 Cesca et al. (2010) showed successful applications 199 to shallow earthquake at regional distances, and 200 was able to derive both point source (best double 201 couple, DC, model, scalar moment and centroid 202 depth) and extended source (fault plane discrim- 203 ination, rupture size, rupture time, rupture nucle- 204 ation) parameters. 205

The first inversion step follows the approach 206 described in Cesca et al. (2010), to obtain the focal 207 mechanism, scalar moment and centroid depth: 208

1. Focal mechanism. We invert amplitude spec- 209 tra of full waveforms, according to Cesca et al. 210 (2010), to derive a point source focal mech- 211 anism (DC, depth and scalar moment); the 212 source epicentral location is assumed to be 213 originally known. 214

2. Polarities. The focal mechanism presents a 215 polarity ambiguity, which can be solved by 216 comparing observed displacements and syn- 217 thetic seismograms for the two possible polar- 218 ity configurations; however, the detection of 219 the true polarity is here not strictly required, 220 as the whole inversion process is carried out 221 in the frequency domain, and only amplitude 222 spectra are involved in the fitting procedure. 223

The source representation through the Kiwi tools 224 allows the adoption of different rise times. For a 225 spatially extended source model, where the rup- 226 ture region is discretised into a number of spatial 227 point sources, the rise time represent the time 228 during which each point source radiates seismic 229 energy. The duration of the whole rupture process 230 is related to rise and rupture times. If we adopt 231 a point source representation, the rise time will 232 represent the duration of the source time function. 233 This parameter was used in Cesca et al. (2010) 234 to have a first, rough, estimate of rupture times 235 and to choose a proper rise time during kinematic 236 source modelling. We proceed here differently: in- 237 stead of determining true duration of the rupture 238 process, we investigate apparent durations as seen 239 by individual stations.

In detail, during the second inversion step, we 241 proceed as follows (Fig. 1 illustrates an example 242 of the main steps, relative to selected seismic 243 
DIVS, Serbia, Epic. distance: $699 \mathrm{~km}$, Azimuth: $-11^{\circ}$
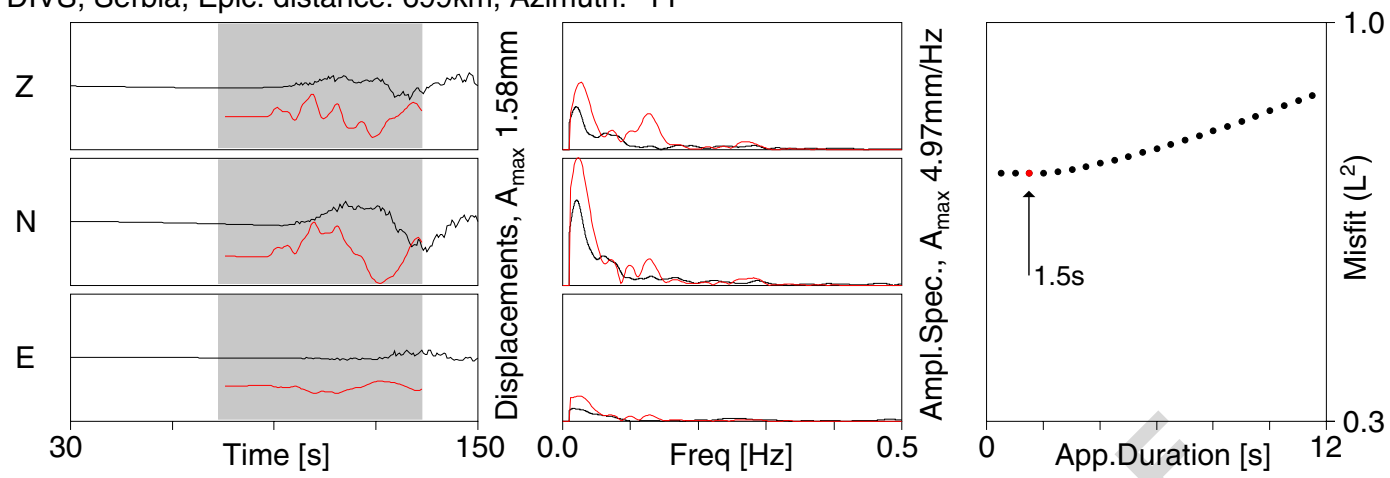

MATE, Italy, Epic. distance: $521 \mathrm{~km}$, Azimuth: $-53^{\circ}$
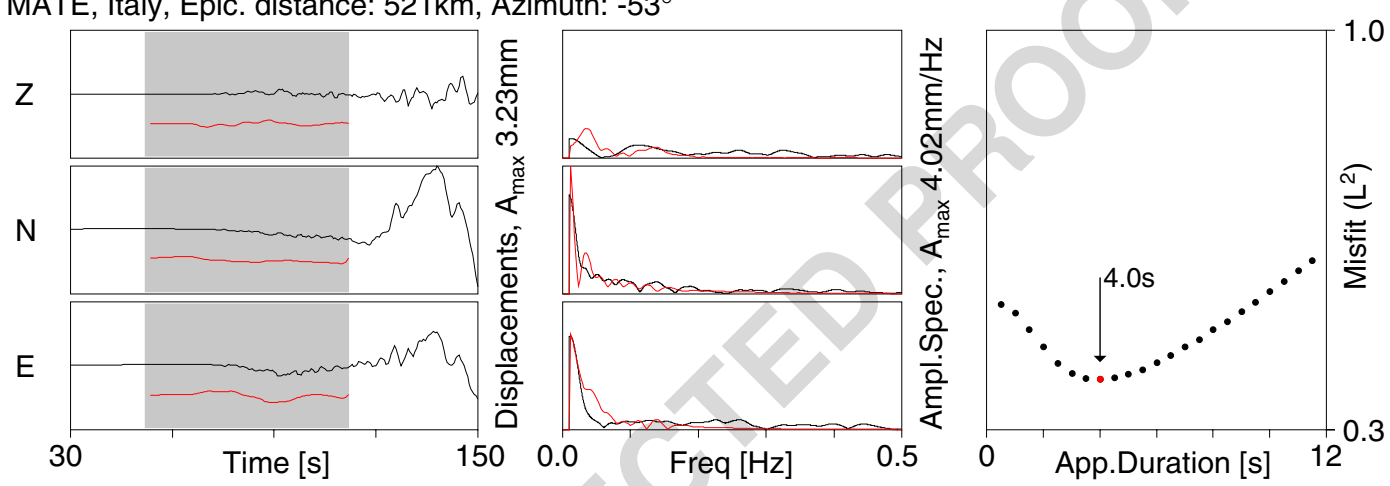

WDD, Malta, Epic. distance $674 \mathrm{~km}$, Azimuth: $-108^{\circ}$
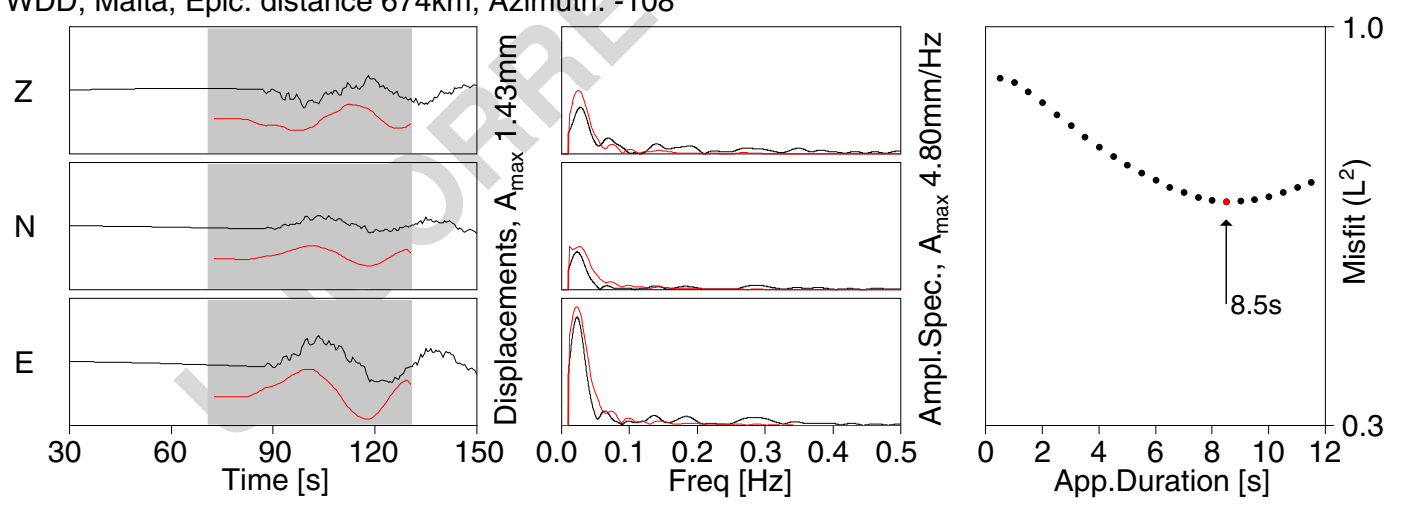

Fig. 1 Example of the procedure followed to derive the apparent source duration at different stations. Selected waveforms, spectra and amplitude spectra inversion results refer to an application to the Andravida earthquake, Greece, which is further extensively discussed in this study. Left: filtered displacements (black lines) and synthetic seismograms (red lines) for the chosen point source model are tapered to select $\mathrm{P}$ waves time windows (grey intervals). Centre: amplitude spectra comparison (red lines correspond to the best fitting synthetic spectra, after comparing several source durations). Right: comparison of amplitude spectra misfit values for different source durations (best solutions for each station are identified by red circles)
244 waveforms from the Andravida earthquake, 245 which is later discussed in the text):

246 1. Waveform selection. We use all available spatial components, preferably using North, East and vertical orientations, rather than rotated 248 traces, in order to have P wave energy on all 249 traces (which is theoretically null on transver- 250 sal components); the presence of more traces 251 for each station has a smoothing effect; after 252 
testing with different datasets, we found that more components provide more stability. We perform a deconvolution of the instrumental response from the data, and conversion to displacements.

2. Tapering. We limit the inversion process to Pwave time windows, which are automatically selected on the base of the source-receiver geometry and theoretical arrival time for the earth model used during the inversion (an arrival time database is calculated in advance, to reduce computational effort at the time of the inversion); for the case studies here described we use $60 \mathrm{~s}$ length time windows, starting $15 \mathrm{~s}$ before theoretical first $\mathrm{P}$ arrival, and apply a bandpass filter in the range $0.01-0.5 \mathrm{~Hz}$ (these parameters may be modified depending on the earthquake size, the source depth, the average duration, and the range of epicentral distances where waveforms are inverted). Tapers should be chosen in order to resolve directivity effects. A minimum length should account at least for two times the average rupture duration and for different periods at the frequency range used for the inversion. For stations located at small epicentral distances, with minor delay between $\mathrm{S}$ and $\mathrm{P}$ phases, tapers may be modified to avoid $\mathrm{S}$ waves.

3. Scalar moment inversion. Since the estimation of the scalar moment may slightly vary depending on the inversion approach (e.g., full waveform or body waves, time domain or amplitude spectra inversion, etc.), we mention here the possibility to perform a specific inversion using an approach consistent with the following directivity inversion. Traces from all seismic stations would be used to invert the scalar moment (e.g. by amplitude spectra inversion, using a Levenberg-Marquardt approach and an $\mathrm{L}^{2}$ norm misfit function). In the following applications this step is not performed, as we count with stable estimations of the scalar moments, provided by the fit of low frequency amplitude spectra from the whole waveforms.

4. Apparent duration inversion. For each of the stations, we perform an amplitude spectra inversion to derive the apparent source duration at that station; the frequency domain inver- sion approach is less sensitive to unmodelled 302 structural heterogeneities; we perform here 303 a grid search for possible durations (for the 304 following case studies, tested durations varies 305 up to $30 \mathrm{~s}$, with an increment of $0.5 \mathrm{~s}$ ); in 306 general we observe smooth single-minimum 307 curves of misfit versus apparent durations, 308 and tests with different inversion approaches 309 (e.g. gradient methods) have shown very con- 310 sistent results with respect to the grid walk 311 procedure.

The apparent source time function durations can 313 be then quickly interpreted in term of simplified 314 laws for finite rupture models. With the aid of 315 synthetic tests and application to selected earth- 316 quake datasets, we will show that, often, it is not 317 necessary to have a complex rupture model to 318 fit the azimuthal distribution of apparent dura- 319 tions. For simple extended source model, such as 320 a one-dimensional linear source or a Haskell bi- 321 dimensional rupture model (Haskell 1964), the 322 effects of directivity can be treated analytically. A 323 unilateral rupture along a horizontal linear source 324 will produce theoretical P-wave pulses of shorter 325 duration for stations located toward the rupture 326 propagation, and larger duration for stations in 327 the opposite direction. Bilateral ruptures result 328 in a minor azimuthal variation of the apparent 329 source time function. A range of asymmetrically 330 bilateral rupture models exists in between. Effects 331 of oblique and vertical rupture propagations may 332 also be modelled but are more difficult to reveal 333 (Beck et al. 1995) and have been more rarely 334 observed (e.g. Eshghi and Zare 2003; Nadim et al. 335 2004).

We originally focus on the two-dimensional 337 problem, with source and observer laying on the 338 same plane. Let us assume a horizontal linear 339 source model of length L, with the rupture starting 340 at one edge (A) and propagating unilaterally till 341 the other edge (B). The rupture time $t_{\mathrm{R}}$ is the time 342 required for the rupture front to propagate along 343 the entire rupture length, from $\mathrm{A}$ to $\mathrm{B}$, at a rupture 344 velocity $v_{\mathrm{R}}$, which is assumed to be constant. The 345 rise time $t_{r}$, defined as the duration of seismic 346 source emission from a point along the source, is 347 here assumed to be constant, according to healing 348 front theory (Nielsen and Madariaga 2003) and 349 
350 will be further considered negligible with respect 351 to the rupture time. Finally, $v_{\mathrm{P}}$ is the average $\mathrm{P}$ 352 wave velocity at the focal region. Typically, rup353 ture propagates with a velocity slightly below the 354 shear wave velocity at the focal region, which also 355 shows a common scale with compressional wave 356 velocity in seismogenic regions. Then, according 357 to Ben-Menahem and Singh (1981), and including 358 the rise time, for a receiver located at azimuth $\varphi$ 359 (defined with respect to the direction of rupture 360 propagation) the apparent source duration $\Delta t(\varphi)$ 361 will be given by:

$$
\Delta t(\varphi)=t_{\mathrm{r}}+\frac{L}{v_{\mathrm{R}}}-\frac{L}{v_{\mathrm{P}}} \cos (\varphi) .
$$

362 In view of a more general formulation, also ac363 counting for asymmetric and pure bilateral rup364 ture, the rupture length $\mathrm{L}$ is divided into two 365 segments $\mathrm{L}_{1}$ and $\mathrm{L}_{2}$, with the following expression 366 for the apparent source duration $\Delta t(\varphi)$ :

$$
\begin{array}{r}
\Delta t(\varphi)=\operatorname{Max}\left[t_{\mathrm{r}}+L_{1} / v_{\mathrm{R}}-\left(L_{1} / v_{\mathrm{P}}\right) \cos (\varphi),\right. \\
\left.t_{\mathrm{r}}+L_{2} / v_{\mathrm{R}}+\left(L_{2} / v_{\mathrm{P}}\right) \cos (\varphi)\right]
\end{array}
$$

367 We can then introduce the following non368 dimensional variables: $\tau(\varphi)$ is the ratio between 369 the apparent source duration $\Delta t(\varphi)$ and the rup370 ture time $t_{\mathrm{R}}, t_{\mathrm{r} / \mathrm{R}}$ is the ratio between rise and 371 rupture time, $v_{\mathrm{R} / \mathrm{P}}$ is the ratio between rupture 372 velocity and $\mathrm{P}$ wave velocity at the source; $\mathrm{L}_{1}$ and $373 \mathrm{~L}_{2}\left(\mathrm{~L}_{1} \geq \mathrm{L}_{2}\right)$ are expressed as $(1-\chi) \mathrm{L}$ and $\chi \mathrm{L}$, 374 respectively, $\chi$ being the ratio between the short375 est segment and the entire rupture length ( $\chi$ may 376 range from 0 , for a pure unilateral rupture, to 0.5 , 377 for a pure bilateral one). The azimuthal depen378 dency of $\tau(\varphi)$, making use of the non-dimensional 379 notation is the following $\left(t_{\mathrm{r} / \mathrm{R}}\right.$ can be in general 380 neglected):

$$
\begin{array}{r}
\tau(\varphi)=\operatorname{Max}\left[t_{\mathrm{r} / \mathrm{R}}+1-v_{\mathrm{R} / \mathrm{P}} \cos (\varphi),\right. \\
\left.t_{\mathrm{r} / \mathrm{R}}+L_{2} / L_{1}+L_{2} / L_{1} \cos (\varphi)\right] .
\end{array}
$$

381 The radiation pattern for three significant cases 382 (pure unilateral, pure bilateral and asymmetric 383 bilateral) is shown in Fig. 2, where we have chosen $384 v_{\mathrm{R} / \mathrm{P}}=0.5\left(v_{\mathrm{R} / \mathrm{P}}\right.$ equal to 0.25 and 1.0 for the slow 385 and fast cases respectively), $\chi$ is equal to $0,1 / 3$ 386 and $1 / 2$ for the three considered cases. We choose 387 different rupture lengths $\mathrm{L}$, in order to have a 388 constant length of the largest rupture segment.
Symmetries of apparent duration radiation pat- 389 terns can be observed, with a one lobe shape for 390 a pure unilateral rupture and a two lobe shape for 391 a pure bilateral one. The theoretical curve of the 392 apparent rupture duration (Fig. 2, right) for the 393 unilateral case range from $t_{r}+t_{\mathrm{R}}-t_{\mathrm{P}}$ (azimuth of 394 rupture direction) to $t_{r}+t_{\mathrm{R}}+t_{\mathrm{P}}$ (opposite direc- 395 tion); its average value is equal to $t_{r}+t_{\mathrm{R}}$ (for a 396 unilateral rupture model $t_{\mathrm{R}}$ and $t_{\mathrm{P}}$ are the rupture 397 time and $\mathrm{P}$ wave travel time along the entire 398 rupture length). For the pure bilateral rupture, the 399 apparent duration varies between $t_{r}+t_{\mathrm{R}}$ (perpen- 400 dicular to rupture direction) to $t_{r}+t_{\mathrm{R}}+t_{\mathrm{P}}$ (paral- 401 lel to rupture direction), with $t_{\mathrm{R}}$ and $t_{\mathrm{P}}$ referring 402 here to half of the rupture length. The larger vari- 403 ation of the apparent duration for the unilateral 404 case, with respect to the bilateral, explains the 405 major difficulties in observing directivity for the 406 second case. Less known is the behaviour of asym- 407 metric bilateral ruptures, although this model is 408 the most general. In this case the radiation pat- 409 tern (Fig. 2, bottom) present a deformed one- 410 lobe shape, with the minimum observed apparent 411 rupture duration at about $45^{\circ}$ from the rupture di- 412 rection of the largest rupture length. The azimuth 413 $\alpha$, where a cusp-like minimum in the apparent 414 duration may be observed, can be obtained by 415 equalizing the two right terms in Eq. 2:

$\alpha=a \cos \left[\frac{(1-2 \chi)}{v_{\mathrm{R} / \mathrm{P}}}\right]$.

Since $v_{\mathrm{R}}$ pertains to $\left[0, v_{\mathrm{P}}\right]$, it follows that for a 417 pure unilateral rupture $(\chi=0)$ we have a sin- 418 gle minimum in direction of rupture propagation, 419 while cusp-like minima are not observed. For a 420 pure bilateral rupture $(\chi=0.5), \alpha= \pm \pi / 2$ always. 421 For the intermediate case of asymmetric bilateral 422 ruptures $(0<\chi<0.5)$, two cusp-like minima are 423 observed if the following condition is met:

$\chi>\frac{\left(1 / v_{\mathrm{R} / \mathrm{P}}\right)}{2}$.

This means that the observation of two minima in 425 the apparent duration curve indicate a dominant 426 bilateral rupture processes.

Figure 2 additionally shows how larger vari- 428 ations in the apparent duration estimations are 429 found, when increasing the rupture velocity (in 430 the figure, effects for an extreme case of $v_{\mathrm{R}}=431$ 
Fig. 2 Theoretical models for pure unilateral (top), pure bilateral (centre) and asymmetric bilateral (bottom) line sources. The ruptures start at a nucleation point (white circles, left plots) and propagate along segments $\mathrm{L}_{1}$ and $\mathrm{L}_{2}$ (black arrows), producing different apparent duration radiation patterns (grey regions, central plots) which have an azimuthal dependence. Right plots present the curves of the apparent duration versus azimuth: thick black lines represent an average behaviour $\left(v_{R}=0.5 v_{\mathrm{P}}\right)$, while dashed lines represent fast $\left(v_{R}=v_{\mathrm{P}}\right)$ and slow $\left(v_{R}=0.25 v_{\mathrm{P}}\right)$ rupture cases. In the case of a partial unilateral rupture, the curve of apparent duration for the average case (thick black line) is given by the maximum of the curves associated to unilateral ruptures along the two segments (thick grey lines)
Line-source unilateral rupture
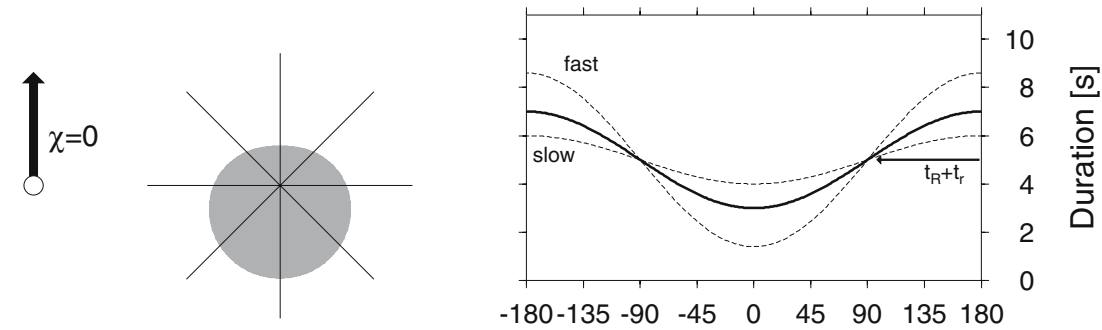

Azimuth [deg]

Line-source bilateral rupture
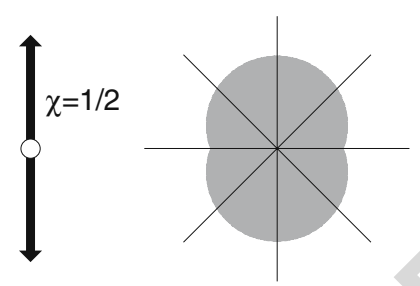

Line-source asymmetric bilateral rupture

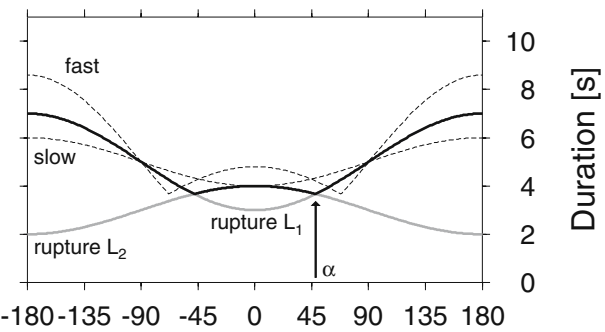

Azimuth [deg]
$432 v_{\mathrm{P}}$ are considered). On the other hand, a slower 433 rupture tends to behave similarly to a spatial point 434 source model (with a finite time duration); Fig. 2 435 shows the case of $v_{\mathrm{R}}=0.25 v_{\mathrm{P}}$, a proportion which 436 is not unrealistic and can be proper for shallow 437 earthquake in sediment layers (e.g. Selby et al. 438 2005; Dahm et al. 2007).

439 For a 3D earth model, directivity effects do not 440 depend only on station azimuth but also on take441 off angles. Equations 1a, $1 \mathrm{~b}$ and 2 will then depend 442 on the angle between the rupture direction and 443 the ray direction at the source, instead than on sta444 tion azimuth. These considerations opened space 445 for specific detailed inversion approaches, such 446 as the successful study by Warren and Shearer 447 (2006), which accounted for take off angles and required a dense station distribution both in terms 448 of azimuthal coverage and range of epicentral dis- 449 tances. We discuss here the problem for the case 450 of unilateral rupture. A first observation is that 451 even for the same source-receiver configuration, 452 different rays travelling along different paths, with 453 different take-off angles, will present different 454 directivity effects. For any considered bodywave 455 with take-off angle $\theta$, we predict theoretically a 456 minor variability of the apparent duration with 457 respect to the one modelled for a planar case. For 458 example, the maximal apparent duration, at the 459 azimuth opposite to the direction of the rupture 460 propagation, will be equal to $t_{r}+t_{\mathrm{R}}+t_{\mathrm{P}} \cos (\theta), 461$ which differs from Eq. 1a. Additionally, we have 462 the superposition of different $\mathrm{P}$ wave arrivals, with 463 
different take-off angles. In any case, the interpretation of the maximal apparent duration following Eq. $1 \mathrm{a}$ and neglecting take-off angles and rise time effects will lead to an overestimation of the terms $t_{\mathrm{R}}$ and $t_{\mathrm{P}}$ and consequently an overestimation of the rupture length. The value derived in such approximation can be safely considered as an upper bound to the real rupture length.

Our approach here is to model only the azimuthal variation of directivity effects. The approximation is limited by different conditions. First, we will focus on shallow earthquakes and use only regional distances seismograms (epicentral distances in the range $200-1,000 \mathrm{~km}$ ), basing our inversion on the fit of time windows centred at the first $\mathrm{P}$ wave arrivals. Additionally, we will consider only the case of horizontal to sub-horizontal ruptures (rupture propagating along direction dipping at most $20^{\circ}$ ). In these circumstances, we will show that the main rupture propagation can be detected even with the approximated approach here described. The interpretation of additional rupture parameters is strongly limited by neglecting take-off angles and rise time effects, and the derived rupture length should be considered as an upper bound to its real value.

On the base of the previous discussion, we can now explain the last step of the inversion approach, where the distribution of apparent source time durations is interpreted in terms of simplified rupture models:

1. Point source model. If we assume a spatial point source model, with a given source time function of duration $t_{r}$, the curve of apparent duration will be a straight line, with no azimuthal dependence. This is the particular case, which can also be described by the previous equations, with $\mathrm{L}=0$, which leads to $t_{\mathrm{R}}=t_{\mathrm{P}}=0$. The model has a unique unknown, $t_{r}$ (by definition, rise time), which represents the apparent rupture time everywhere.

2. Pure/predominant unilateral rupture. In this case, the azimuthal distribution of apparent durations is expected to follow a sinusoidal behaviour. The fit is expected to be larger in case of a pure unilateral rupture, but the model can still well reproduce data also for asymmetric bilateral ruptures. In both cases, the minimum of the curve will indicate the main rupture 512 direction $\left(\varphi_{0}\right)$. The model is represented by 513 the curve of the apparent duration $\Delta t(\varphi)$ : $\quad 514$

$\Delta t(\varphi)=-A \cos \left(\varphi-\varphi_{0}\right)+B$

with $\mathrm{A}$ and $\mathrm{B}$ positive, describing in first approx- 515 imation the travel time of $\mathrm{P}$ waves along the rup- 516 ture length $\left(t_{\mathrm{P}}\right)$ and the sum of rise and rupture 517 times $\left(t_{r}+t_{\mathrm{R}}\right)$.

3. Pure bilateral rupture. In case of a pure bilat- 519 eral rupture, we will use the following curve, 520 instead:

$\Delta t(\varphi)=A\left|\cos \left(\varphi-\varphi_{0}\right)\right|+B$.

4. Comparison of directivity models. Since 522 Eqs. 5 and 6 are dependent on three unknown 523 parameters, while the standard average rup- 524 ture time has only one (the average earth- 525 quake duration or duration of the common 526 source time function), they will always pro- 527 vide a better fit with respect to the common 528 rupture duration model. An $F$ test can than 529 be used to evaluate the misfit improvement 530 versus the increase of degrees of freedom. $F 531$ values above 0.5 will be used here to prefer 532 unilateral or bilateral models with respect to 533 the point source solution. The modelling of 534 asymmetric bilateral rupture requires more 535 free parameters, being the superposition of 536 two functions as in Eq. 5. Chances for the im- 537 plementation of such a model are highly lim- 538 ited by several factors, including data quality, 539 focal mechanism, epicentral azimuthal cover- 540 age and local structural heterogeneities. We 541 suggest here the adoption of this model only 542 for specific cases rather than its implementa- 543 tion within the automated processing.

The major advantages of the presented approach 545 are that only point source synthetic seismograms 546 are used, so that forward modelling and inversion 547 are fast. A second advantage lies in the intrinsic 548 simplicity of this approach, which provides simple 549 plots of easy interpretation and suggest its imple- 550 mentation for automated routines. In the worse 551 case, if no clear pattern is detected, the retrieved 552 information can still be used to better focus a 553 more detailed full waveform kinematic inversion 554 
585 Before applying the method to real data, and in 586 order to assess the method performance, we carry 587 out a set of inversions using synthetic datasets. 588 We generate synthetic seismograms first for lin589 ear sources and consequently to planar ones. 590 Considered source models present different sig591 nificant focal mechanisms and directions of rup592 ture propagation. Both synthetics for linear and 593 planar sources are generated using the Kiwi tools 594 (http://kinherd.org; Heimann 2010), assuming the 595 PREM model (Dziewonski and Anderson 1981). 596 The inversion is then carried out as described in 597 the previous paragraph, assuming a spatial point 598 source. Focal mechanisms, scalar moment and 599 depth are retrieved at a first stage, by using the 600 method described in Cesca et al. (2010), which has been here specifically modified in order to include 601 the retrieval of the apparent rupture time at each 602 station. In the synthetic tests, a dense grid of 154603 stations is considered, in order to plot apparent 604 duration contours. Stations location accomplish 605 to the chosen conditions in terms of epicentral 606 distances.

Three line source mechanisms (strike-slip (SS) 608 strike $\varphi=30, \operatorname{dip} \delta=90$, rake $\lambda=0$; normal fault 609 (NF) $\varphi=30, \delta=45, \lambda=90$; thrust fault (TF) $\varphi=610$ $30, \delta=20, \lambda=-90$ ) and three rupturing mod- 611 els (pure unilateral, asymmetric bilateral, pure 612 bilateral) are considered at first, thus providing 613 a set of nine source models. Ruptures propagate 614 horizontally for the strike-slip and normal fault, in 615 direction NNE-SSW, and toward ESE along the 616 low-angle dipping plane, for the thrust fault. The 617 source model centroid is always located at a depth 618 of $20 \mathrm{~km}$, the source length is $30 \mathrm{~km}$, rupture ve- 619 locity is $3.5 \mathrm{~km} / \mathrm{s}$. Pure unilateral ruptures start at 620 the southern (SS, NF) or western (TF) edge. The 621 same main rupture direction is used for asymmet- 622 ric bilateral ruptures, the two ruptured segments 623 having lengths $\mathrm{L}_{1}=22.5$ and $\mathrm{L}_{2}=7.5 \mathrm{~km}$. Rise 624 time is fixed to $2 \mathrm{~s}$ in all cases. The inversion 625 is carried out using $40 \mathrm{~s}$ time windows, starting 626 $10 \mathrm{~s}$ before the theoretical arrival of P phases. A 627 frequency bandpass, between 0.01 and $0.5 \mathrm{~Hz}$, is 628 used to filter Green's functions and data. Inver- 629 sion results are shown in Fig. 3. Coloured surface, 630 representing the inverted apparent source dura- 631 tion, highlight the radiation patterns of apparent 632 duration. The azimuthal distribution of apparent 633 duration clearly shows directivity effect and its 634 minor dependence on epicentral distance using 635 our approach and proof that a good quality fit 636 can be achieved using the simplified azimuthal de- 637 pendent curves. In particular, the fit of the cosine 638 curve described by Eq. 5 can be used to detect uni- 639 lateral or asymmetric bilateral ruptures, while the 640 curve from Eq. 6 to detect pure bilateral ruptures. 641 Rupture directivity is correctly detected in all 642 cases, with the exception of the bilateral rupture 643 along the low-dipping angle plane of the thrust 644 mechanism (Fig. 3, bottom right), where unilateral 645 rupture is incorrectly estimated. The reason for 646 this discrepancy can be described as follows. Since 647 the extended source is not horizontal, the seg- 648 ment toward ESE and WNW are located below 649 


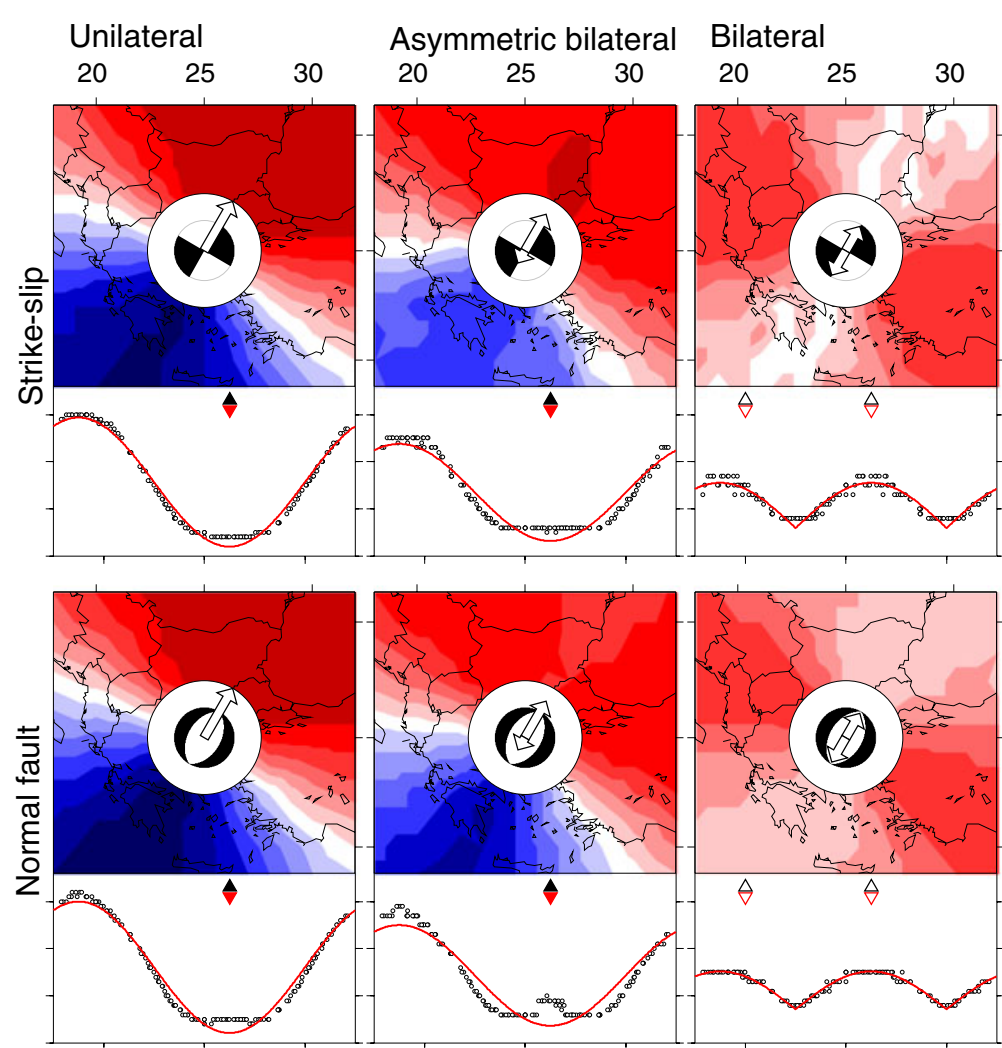

\section{Apparent}

duration [s]

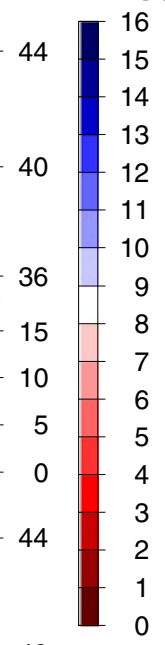

40
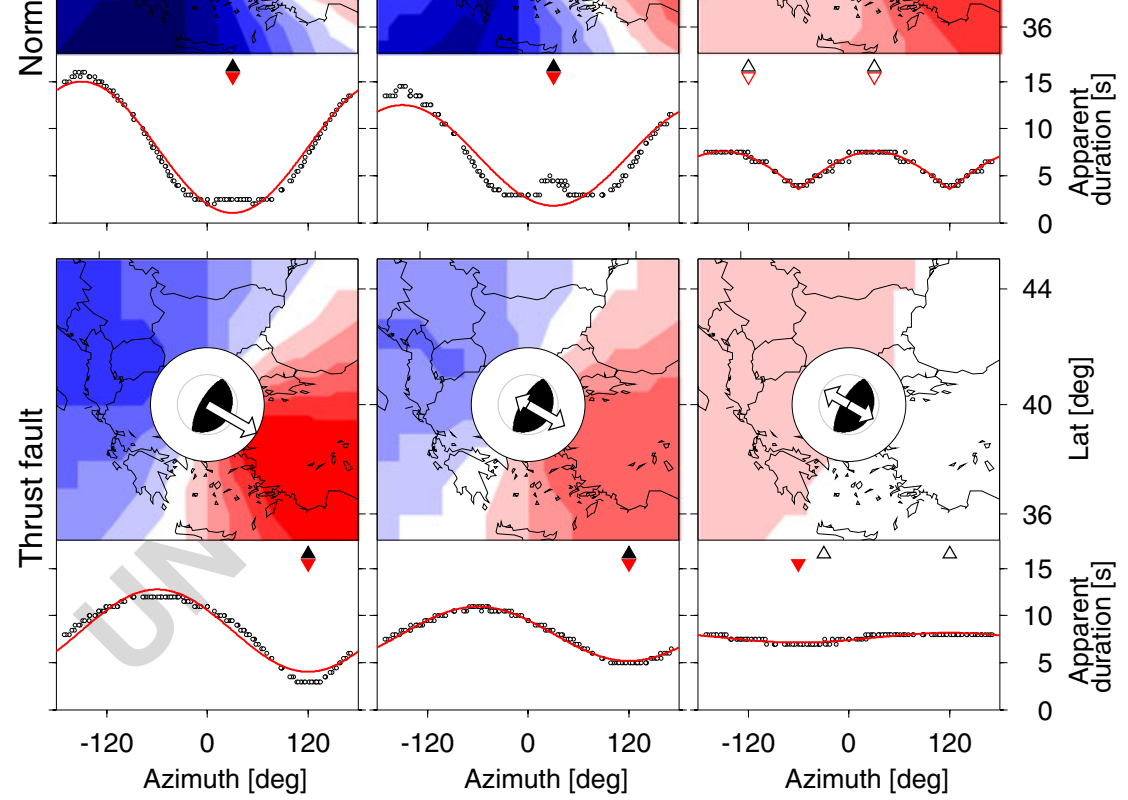

44

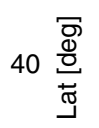

36

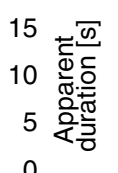

Fig. 3 Inversion results for linear sources. We consider three focal mechanisms (strike-slip, top; normal fault, centre; thrust fault, bottom) and three rupture processes (pure unilateral, left; asymmetric bilateral, centre; pure bilateral, right). For each case, we show colour plots representing the inverted apparent duration at a dense grid of station around the epicentre (red to blue scale represents increasingly longer apparent durations). The focal mechanisms are shown at the epicentral location, together with white arrows describing rupture directions (arrow sizes are proportional to rupture lengths). Graphics below each colour plot represent the apparent duration versus azimuth (dots) and the best fitting model (red curves). Upper triangles represent the correct solution (a single black triangle is plotted at the proper azimuth for unilateral and asymmetric bilateral ruptures; two white triangles indicate rupture directions for pure bilateral rupture cases). Inverted triangles represent inversion results (single red triangle for unilateral and asymmetric bilateral ruptures, two white triangles for pure bilateral ruptures) 
650 and above the centroid depth, respectively. Since 651 we use a layered model, the frequency content 652 of synthetic seismogram varies from shallower to 653 deeper sources, as well as take off angles. These 654 effects, which cannot be reproduced by a point 655 source located at the centroid depth, results larger 656 than those related to the bilateral rupture, thus 657 explaining the detection of an apparent directivity 658 towards dip direction.
Given the successful application to line sources, 659 we simulate now more realistic rupture processes, 660 generating synthetic seismograms for the eikonal 661 source model (Heimann 2010; Cesca et al. 2010). 662 We use here circular faults, with rupture propagat- 663 ing with a variable velocity, scaling by a coefficient 664 0.9 with shear wave velocity in the crustal model. 665 Given the adoption of the PREM model, the 666 source depth and its extension, rupture velocity 667
Fig. 4 Inversion results for circular eikonal sources. For each of the nine considered source models, we show colour plots representing the inverted apparent duration around the epicentre (red to blue scale represents increasingly longer apparent durations). Graphics below each coloured plot represent the apparent duration versus azimuth (dots) and the best fitting model (red curves). We use the same symbol convention as in Fig. 3

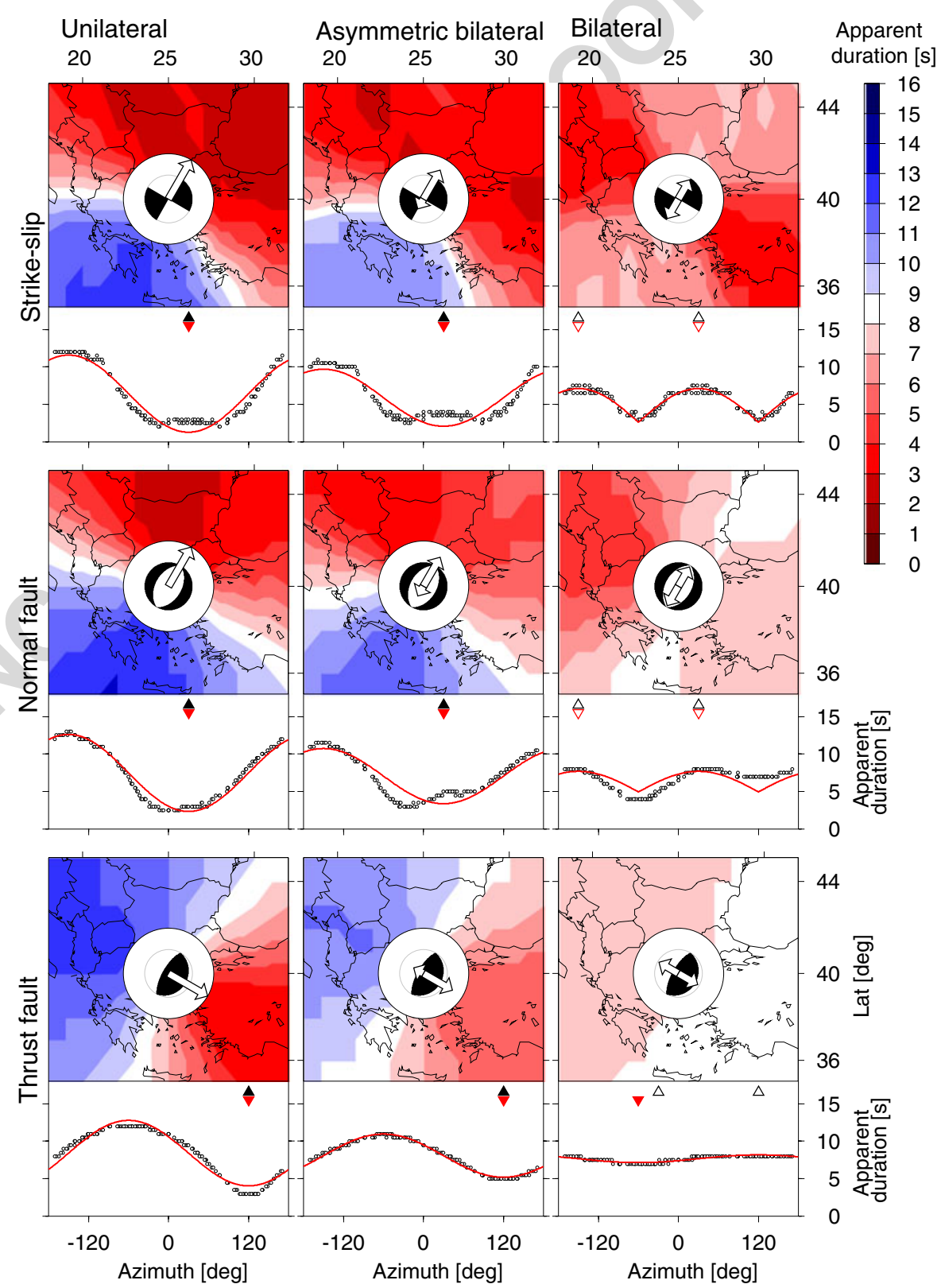


668 range between 2.9 and $4.0 \mathrm{~km} / \mathrm{s}$. Inversion is car669 ried out using the same approach and parameters 670 as for the previous test and results summarized in 671 Fig. 4. The main characteristics of the azimuthal 672 patterns of the apparent rupture duration are pre673 served. Directivity effects can be detected and 674 modelled for all pure unilateral and asymmetric 675 bilateral ruptures, although the fit quality results 676 in some cases significantly poorer than for line 677 source cases. The adoption of bi-dimensional rup678 tures, and specifically the inclusion of sources at 679 different depths, slightly modifies the apparent 680 duration pattern, as can be seen by the compari681 son of plots in Figs. 3 and 4 relative to normal fault 682 mechanism. The modification of the apparent 683 rupture radiation pattern has similar causes than 684 those described for linear sources. Additionally, 685 it is here also depending on the variable rupture 686 velocity (which, according to the crustal model, 687 is faster for deeper sources than for shallower 688 ones). These effects result critical for the inversion 689 of a bilateral rupture for the case of a thrust 690 fault mechanism, which is erroneously interpreted 691 as unilateral (with a rupture propagation in dip 692 direction). On the other hand, the discrimination 693 between pure and asymmetric bilateral rupture is 694 not always possible; the observation of the charac695 teristic lobe associated to the asymmetric bilateral 696 rupture may indicate such a rupture process, but 697 could not be sufficient, alone, to distinguish this 698 case to a pure unilateral rupture.

699 A variation of the scalar moment will lead to a 700 scaling of synthetic seismograms and modify their 701 amplitude spectra. As a consequence, the inver702 sion of apparent durations may lead to slightly 703 different results. In order to investigate these 704 effects, we have perturbed the scalar moments 705 used for synthetic tests, and analyse inversion 706 results. While the uni- or bilateral mode of the 707 rupture and the main rupture direction are not 708 influenced by a variation of the scalar moment and 709 are always correctly retrieved, the rupture time 710 and the following estimation of rupture lengths 711 suffer slight changes. A perturbation of $10 \%$ of 712 the correct scalar moment always led to uncer713 tainties below 5\% in terms of rupture time and 714 rupture length. Synthetic tests suggest the imple715 mentation of the method here proposed towards a 716 rapid detection of directivity effects. Additionally, these tests point out specific cases, where the in- 717 version approach results more critical, and where 718 a careful discussion of results is suggested. In gen- 719 eral, horizontal ruptures and pure or partially uni- 720 lateral ruptures are more easily detected, whereas 721 pure bilateral sources and rupture propagating 722 along dipping directions may be more problematic 723 to resolve.

\section{The Andravida 8.6.2008 earthquake}

On June 8th, 2008, a magnitude Mw 6.4726 earthquake struck NW Peloponnese, Greece. 727 The earthquake, here further referred as the 728 Andravida earthquake, produced two casual- 729 ties, about 100 injuries and several damages 730 (Chouliaras 2009). A wide number of studies cov- 731 ered the earthquake source and its effects. A pure 732 strike-slip focal mechanisms was unanimously 733 provided by several institutions and catalogues 734 surveying regional and global seismicity, includ- 735 ing National Observatory in Athens (NOA), 736 Aristotle University of Thessaloniki (AUTH), 737 INGV European-Mediterranean RCMT Cata- 738 logue (INGV-RCMT), Swiss Federal Institute 739 of Technology, United States Geological Sur- 740 vey (USGS) and Global CMT Catalogue (CMT). 741 According to these models, fault planes are al- 742 most vertical and oriented NNE-SSW and WNW- 743 ESE. Source depth estimations showed some 744 variability, ranging between 10 and $38 \mathrm{~km}$, and 745 magnitudes $\mathrm{Mw}$ ranged between 6.3 and 6.5. 746 The epicentral locations of the earthquake after- 747 shocks (Ganas et al. 2009; Gallovic et al. 2009; 748 Kostantinou et al. 2009), which are distributed 749 within a narrow strip extending NNE-SSW, pro- 750 vide a convincing image of the rupture orienta- 751 tion. The cloud of aftershocks elongates for about 752 30-35 km, providing a first rough estimation of 753 rupture size. The aftershock distribution is denser 754 towards the Northern edge. To the south, epi- 755 central locations may indicate a minor bending 756 of the rupture area to a slightly larger strike. 757 All published source models are consistent with 758 the identification of the NNE-SSW striking fault 759 plane. Sokos et al. (2008), using hypocentral- 760 centroid relative location method, identified the 761 same plane; since centroids locations are generally 762 
763 located North of hypocentral locations, some indi764 cation for a dominant propagation towards North 765 may arise from this study. Even more convincing, 766 with respect to the detection of directivity, are 767 the studies of Kostantinou et al. (2009), Gallovic 768 et al. (2009) and Cesca et al. (2010). The first 769 authors derived a finite source model, also con770 sistent with their aftershock relocations, finding 771 a rupture length of $22.4 \mathrm{~km}$ and an asymmetric 772 bilateral rupture, with a major rupture along the 773 NE branch. Gallovic et al. (2009) used a conjugate 774 gradient method to detect the spatio-temporal 775 evolution of the rupture process. Results indicate 776 a predominantly unilateral rupture, propagating 777 along a main slip patch, with a rupture length 778 of about $20 \mathrm{~km}$ and a rupture velocity of about $7793 \mathrm{~km} / \mathrm{s}$. Cesca et al. (2010), based on amplitude 780 spectra inversion of full waveform and assuming an eikonal source model, detected an asymmet- 781 ric rupture propagation, with a predominance of 782 rupture propagation towards NNE; the rupture 783 length was estimated $40 \mathrm{~km}$, while the average 784 rupture velocity was fixed to about $3.2 \mathrm{~km} / \mathrm{s}$. The 785 consistency of these results (see Fig. 5 bottom), 786 obtained with different methods and datasets, 787 offer a serious reference to our study in terms of 788 fault plane identification and rupture directivity. 789

In our inversion, we assume the epicentral lo- 790 cation provided on the EMSC-CSEM webpage 791 and the focal mechanism determined by Cesca 792 et al. (2010), which is based on the fit of full 793 waveform amplitude spectra. We observed that 794 a new estimation of the scalar moment, based 795 on the fit of $\mathrm{P}$ wave spectra only, would present 796 minor variation with respect to the assumed value 797 (5.97e18 instead of $6.07 \mathrm{e} 18 \mathrm{Nm}$ ). Then, we invert 798
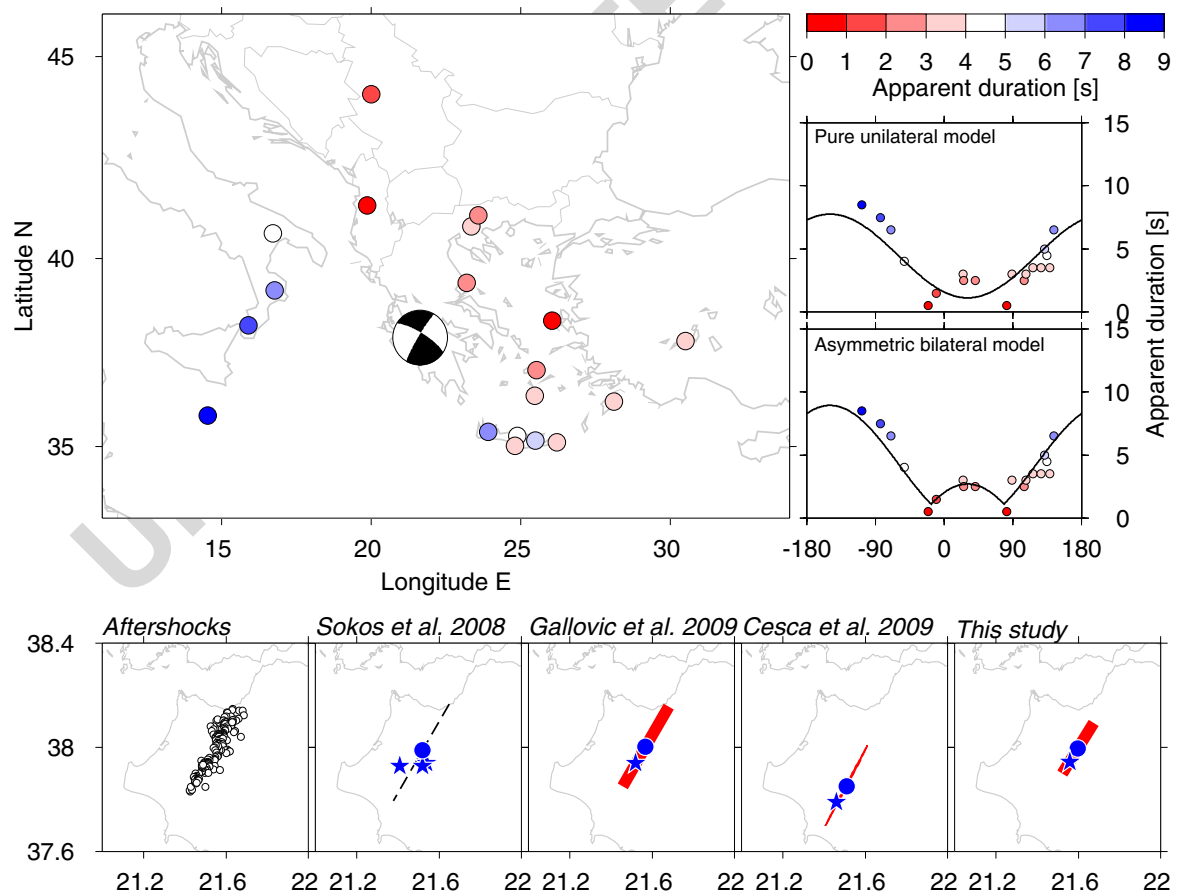

Fig. 5 Inversion results for the Mw 6.4 Andravida (NW Peloponnese) earthquake (top) and comparison with published source models (bottom). Top: coloured dots represent the inverted apparent duration at the stations used, according to the given colour scale; the azimuthal distribution of apparent durations may be fitted (top right) assuming a pure unilateral or, better, a partially unilateral rupture (thick lines). Bottom: the comparison of aftershocks distribution (after Gallovic et al. 2009) identifies the NNE-SSW rupture plane in agreement with centroidhypocentral technique (Sokos et al. 2008), adjoint method (Gallovic et al. 2009), full waveform kinematic inversion (Cesca et al. 2010) and our results; the last four methods consistently detect a partially unilateral rupture towards NNE. Stars and blue circles represent here nucleation points and centroids respectively; the rupture area is plotted in red 
799 for the apparent duration at each station sep800 arately and plot resulting values in function of 801 station azimuth (Fig. 5), according to the discussed 802 methodology. As a first approximation, we try to 803 fit apparent durations by means of pure unilateral 804 and pure bilateral rupture models, assuming both 805 fault planes. Since fault planes are almost vertical, 806 only horizontal directions of the rupture velocity 807 along these planes are considered. The unilateral 808 rupture model with rupture propagation towards 809 NNE provide a very good fit to the apparent du810 ration data, and is preferred to remaining models 811 on the base of the F test. This result provides a 812 clear indication for a rupture propagating towards $813 \mathrm{NNE}$, and thus can be used to discriminate the 814 true fault plane (NNE-SSW) from the auxiliary 815 one (WNW-ESE). Based on the good fit, we try 816 to refine our solution by investigating asymmetric 817 bilateral ruptures. Results provide an even more 818 convincing fit (Fig. 5, bottom right), when an 819 asymmetric bilateral source model with rupture 820 propagating mostly Northward is assumed, as the 821 curve account for the two symmetric minima at 822 about -21.5 and $82.5^{\circ}$ and the internal charac823 teristic lobe of asymmetric rupture (see Fig. 2, 824 bottom). On the other side, this result is in very 825 good agreement with published models discussed 826 before. According to the previous discussion for 827 a simplified bidimensional case, the maxima of 828 the two cosine curves associated to the rupturing 829 of two segments of the fault are equal to $t_{\mathrm{P}}+$ $830 t_{\mathrm{R}}+t_{r}$, where these terms refer to the $\mathrm{P}$ wave 831 propagation, rupture and rise time related to each 832 segment. The maxima of the apparent duration 833 curve are equal to $8.9 \mathrm{~s}$ (segment $\mathrm{L}_{1}$ toward NNE) 834 and $2.7 \mathrm{~s}$ (segment $\mathrm{L}_{2}$ toward SSW). Assuming 835 an average $\mathrm{P}$ wave velocity of $8 \mathrm{~km} / \mathrm{s}$ (consistent 836 with the used velocity model at the hypocentral 837 depth), a rupture velocity of $3 \mathrm{~km} / \mathrm{s}$ (consistent 838 with Gallovic et al. 2009), and considering the rise 839 time negligible with respect to rupture time, we 840 obtain rupture lengths of about 19 and $6 \mathrm{~km}$. The 841 total length of about $25 \mathrm{~km}$ for the main patch 842 is in general agreement with most of published 843 results. We observe a discrepancy with the rupture 844 size of about $40 \mathrm{~km}$ determined in Cesca et al. 845 (2010). This last value might be overestimated, 846 as the adopted full waveform kinematic inversion 847 may in some cases be affected by a trade-off be- tween different source parameters. The observed 848 discrepancy may also indicate a different response 849 of the two approaches to the rupture process and 850 energy emission, with the full waveform inver- 851 sion detecting the largest rupture length, and the 852 directivity inversion identifying the main rupture 853 patch. The upper limit value we found here is 854 slightly larger than the length estimated by stan- 855 dard empirical relations (according to Wells and 856 Coppersmith 1994, the average rupture length for 857 a Mw 6.4 is about $14 \mathrm{~km}$ ). We remark that the 858 interpretation of inversion results to this extent 859 should be carried out only in best conditions, 860 where the fitting of the apparent duration curve 861 is good enough to further interpret it.

862

\section{The SW Peloponnese 14-20.2.2008 seismic sequence}

A seismic sequence struck the region offshore 865 SW Peloponnese, Greece, in the days following 866 February 14th, 2008, with three major earth- 867 quakes occurring within a week. On February 868 14th, a first Mw 6.8 (magnitude estimated by 869 EMSC-CSEM and Cesca et al. 2010) event struck 870 the region at 10:09 UTC. Two hours later, at 871 12:08, UTC, a Mw 6.2 aftershock occurred. Fi- 872 nally, on February 20th (18:27 UTC), a Mw 6.2873 event took place. Focal mechanisms (EMSC- 874 CSEM webpage) indicate thrust faulting for the 875 first two events, while the last one has a different, 876 strike-slip mechanism, with fault planes striking 877 ENE and NNW. Source depths, according to 878 EMSC-CSEM catalogue, were 30, 20 and $25 \mathrm{~km}, 879$ respectively, for the three earthquakes. Whereas 880 different institutions (e.g. NOA, AUTH, Uni- 881 versity of Patras UPSL, INGV-RCMT, USGS, 882 CMT) provided point source solutions for these 883 events, few trials has been carried out so far to 884 interpret rupture kinematics (Roumelioti et al. 885 2009; Cesca et al. 2010). A strongly uneven sta- 886 tion distribution and large epicentral gaps toward 887 SW have possibly limited source modelling until 888 now. Based on full waveform inversion, Cesca 889 et al. (2010) identified the ENE-WSW plane for 890 the strike-slip earthquake of February 20th, and 891 a partial unilateral rupture towards the coast was 892 found. For the first two earthquakes, the low angle 893 
894 planes dipping toward NW were preferred, but the 895 inversion results were not completely satisfacto896 rily. Roumelioti et al. (2009) adopted an empirical 897 Green's functions approach, using the Mw 6.2 898 aftershock to model the finite fault of the largest 899 earthquake; their results support the identification 900 of the low angle dipping plane as well as directivity 901 towards SSW. Finally, the identification of low 902 dip angle rupture planes in this region for thrust 903 earthquakes would agree with local tectonics, as904 sociating the earthquake occurrence to oceanic 905 subduction (Underhill 1999).

906 Figure 6 summarizes our inversion results. 907 Differently from the application to the Andravida 908 earthquake, apparent durations for the earth- quakes occurring on February 14th show a major 909 spreading and are worse fitted by the simplified 910 cosine function we associated to pure unilateral 911 ruptures. A better fit, and minor spreading, is 912 observed for the main event, with respect to its 913 aftershock. However, for both two earthquakes, a 914 general trend can be detected, indicating a mini- 915 mum of the cosine curve for an azimuth of about 916 $135^{\circ}$, which suggests a main direction of the rup- 917 ture propagation towards SE. These results are 918 unable by themselves to provide further informa- 919 tions about the true fault plane, as they may be 920 modelled either assuming the low-angle and the 921 steep dipping plane. A better fit is obtained for the 922 February 20th earthquake: clear directivity effect 923
Fig. 6 Inversion results for the February 14th, 2008, Mw 6.8 (top), the February 14th, 2008, Mw 6.2 (centre) and the February 20th, 2005, Mw 6.2 (bottom) earthquakes, offshore SW Peloponnese. For each earthquake, coloured dots represent the inverted apparent duration at the stations used, according to the colour scale given for each case; the azimuthal distribution of apparent durations (right) may be fitted assuming unilateral ruptures (thick black lines). Inverted triangles indicate the retrieved rupture directions

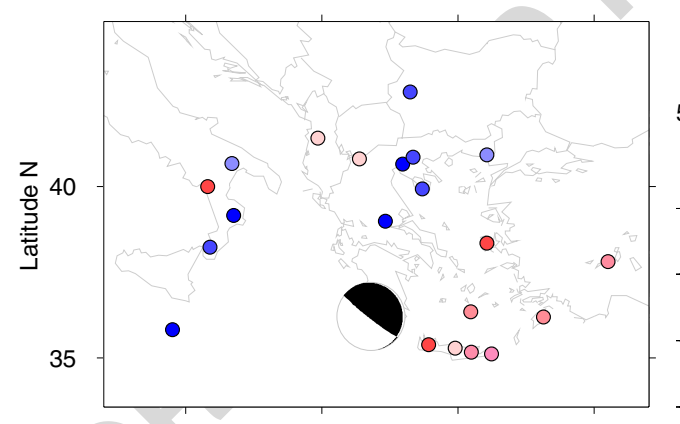

SW Pelponnese 14.02.08, 10:09, Mw 6.8
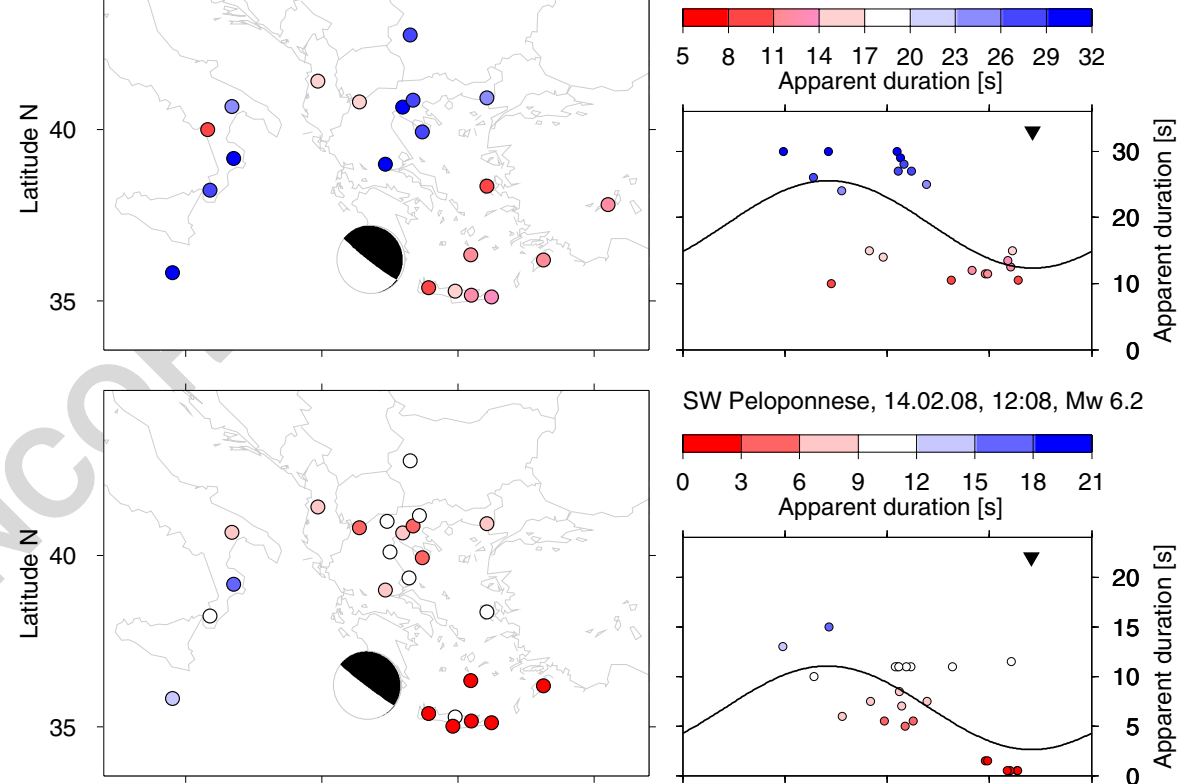

SW Peloponnese, 14.02.08, 12:08, Mw 6.2
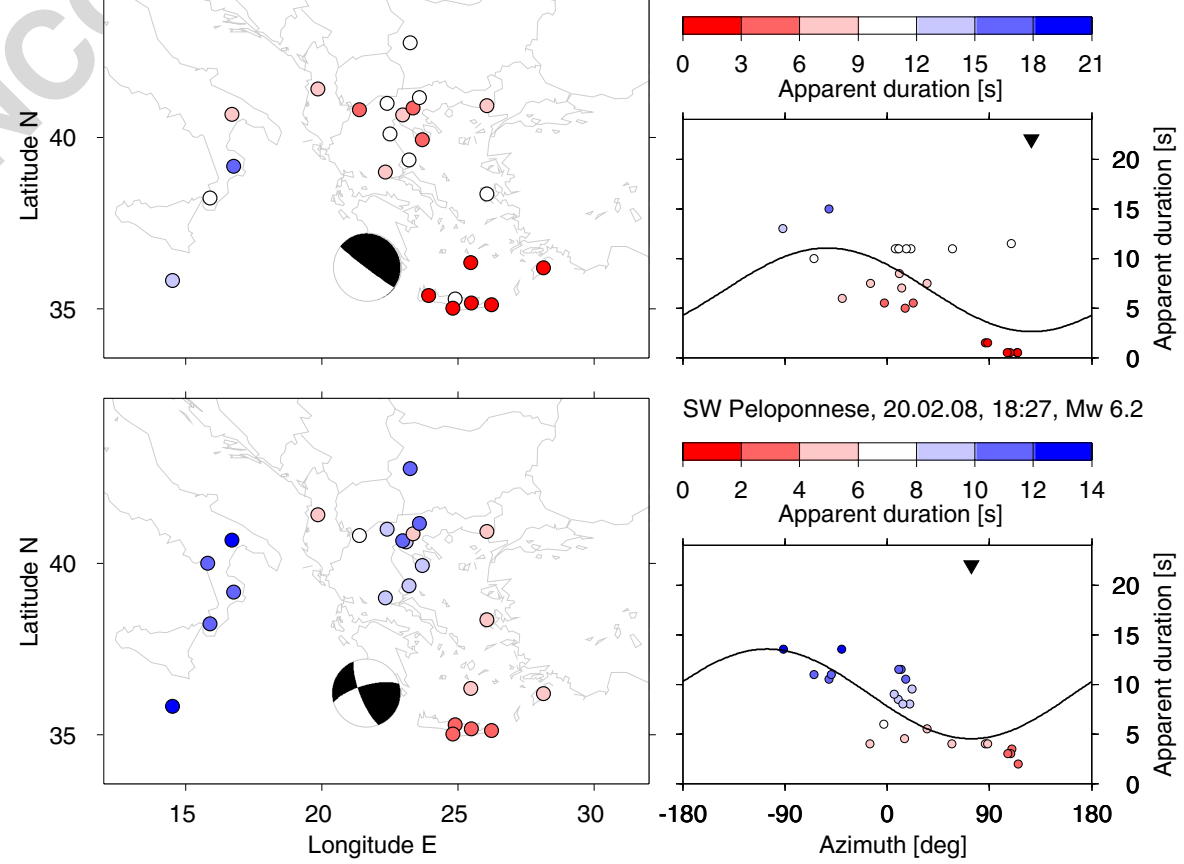

SW Peloponnese, 20.02.08, 18:27, Mw 6.2
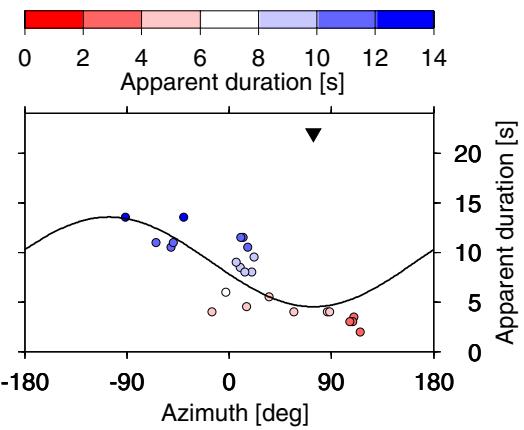
924 is here retrieved, indicating a rupture mostly prop925 agating towards ENE, thus along the WSW-ENE 926 fault plane. The differentiation between pure or 927 partial unilateral rupture may be here rewarded 928 as beneath the limit of a safe data interpretation, 929 but we observed how the general result is in well 930 agreement with previous results by Cesca et al. 931 (2010), where the source model was derived by 932 the fit of high-frequency (up to $0.1 \mathrm{~Hz}$ ) amplitude 933 spectra from the whole waveforms.

934 Finally, we investigate effects of the assumption 935 of imprecise point source parameters on the esti936 mation of rupture directivity. The effects of anom937 alous source depth estimation are studied for the 938 February 20th aftershock, as different Institutions 939 have provided a range of different values ranging 940 from 8 to $25 \mathrm{~km}$. We repeated the inversion using 941 a different point source solution (strike $249^{\circ}$, dip $94288^{\circ}$, rake $-12^{\circ}$, depth $12 \mathrm{~km}$ ), as provided by the 943 INGV European-Mediterranean RCMT Catalog; 944 this focal mechanism is similar to our solution and 945 major differences concern centroid depth, which is 946 now shallower. Directivity inversion remains very 947 stable, showing a consistent identification of uni948 lateral rupture direction toward SE, and indicates 949 that a source depth variation of about $10 \mathrm{~km}$ does 950 not result in any significant variation in the radia951 tion pattern of apparent duration. In a similar way, 952 we tested slightly different focal mechanisms for 953 both earthquakes of February 14th: even if our fo954 cal mechanisms are in relatively good agreement 955 with other published solutions, some difference 956 can be observed. For example, the INGV-RCMT 957 catalogue indicates strike angles of $333^{\circ}$ and $298^{\circ}$, 958 for these earthquakes, which differ from our so959 lution $\left(347^{\circ}\right.$ and $341^{\circ}$ respectively). Even in this 960 case, after adopting the source parameters pro961 vided by INGV-RCMT, the inversion results are 962 stable, with the detection of main rupture direc963 tions pointing towards SE-ESE.

\section{Conclusions}

965 We propose here a new method for a quick detec966 tion of directivity effects for shallow earthquakes 967 at regional distances. Among the most important features of the method, we highlight here the 968 following ones: $\quad 969$

- Rapid inversion

The assumption of spatial point source allows 971 an extremely rapid generation of synthetic seis- 972 mograms and point source parameters inversion, 973 thus offering a tool to early detect directivity; to 974 quantify such improvement, on a standard single 975 processor PC the inversion of directivity is here 976 carried out within a minute, about 20 times faster 977 than the full kinematic inversion for the same 978 event, using the approach described in Cesca et al. 979 (2010).

\section{- Coherent inversion}

The use of the Kiwi tools for data processing 982 and inversions improves significantly the consis- 983 tency of our methodology: for example, the same 984 dataset and the same inversion tools can be used 985 to first derive the focal mechanism, then the scalar 986 moment and finally the apparent duration; we 987 believe this consistency between data used for 988 different inversions significantly improve the co- 989 herency of the inversion approach.

- Accounting for wave propagation

The method is based on amplitude spectra inver- 992 sion, using theoretical Green's functions for the 993 chosen earth model. In this way, we account for 994 wave propagation effect, an improvement with 995 respect to standard methods based on pulse length 996 estimations.

- No requirements of specific aftershocks

Avoiding the use of empirical Green's function, 999 the method is not limited by the existence of 1000 a proper aftershock, nor need to wait for its 1001 occurrence.

- Automation 1003

The adoption of the Kiwi tools and the simplicity 1004 of the inversion approach made possible the im- 1005 plementation of the method as automated routine. 1006

In this manuscript we have demonstrated the 1007 method performance, both with a range of syn- 1008 thetic tests and with observed data for different 1009 
1010 shallow earthquakes recently occurred. These ap1011 plications offer indications about the quality and 1012 extent of inversion results. The retrieval of pure 1013 unilateral and pure bilateral ruptures is in gen1014 eral better resolved than asymmetric ruptures, 1015 although the application to the June 8th, 2008, 1016 Andravida earthquake showed that this case can 1017 also be detected, in favourable conditions. In 1018 general, directivity effects are better resolved for 1019 strike slip earthquakes, with respect to normal or 1020 thrust faulting. Directivity detection offers often a 1021 chance to identify the rupture plane, discriminat1022 ing it from the auxiliary one. The determination 1023 of rupture time, rise time and rupture velocity on 1024 the base of the proposed method is beyond its 1025 purposes and should require a careful supervision. 1026 We have here focused to earthquake with magni1027 tudes of Mw 6 to 7 and shallow hypocentres. The 1028 extension of this inversion approach for the study 1029 of other range of magnitudes or deeper sources 1030 may be investigated in future.

1031 Acknowledgements We thank Prof. J. Zahradnik and 1032 two anonymous reviewers for useful comments and sug1033 gestions. The facilities of GEOFON and IRIS Data 1034 Management System, and specifically the IRIS Data Man1035 agement Center, were used for access part of the waveform 1036 and metadata required in this study. We acknowledge all 1037 institutions providing seismic data used in this research: 1038 GEOFON, MEDNET Project, Greek National Seismic 1039 Network and Aristotle University Thessaloniki Network. 1040 Maps and focal mechanisms have been plotted with GMT 1041 (Wessel and Smith 1998). This work has been funded by the 1042 German DFG project KINHERD (DA478/14-1/2) and the 1043 German BMBF/DFG "Geotechnologien" project RAPID 1044 (BMBF07/343).

\section{References}

1046 Beck SL, Silver P, Wallace TC, James D (1995) Directivity 1047 analysis of the deep Bolivian earthquake of June 9, 1048 1994. Geophys Res Lett 22:2257-2260

1049 Ben-Menahem A (1961) Radiation of seismic surface 1050 waves from finite moving sources. Bull Seismol Soc 1051 Am 51:401-453

1052 Ben-Menahem A, Singh SJ (1981) Seismic waves and 1053 sources. Springer, New York

1054 Bernard P, Madariaga R (1984) A new asymptotic method 1055 for the modelling of near-field accelerograms. Bull 1056 Seismol Soc Am 74:539-557
Beroza GC, Spudich P (1988) Linearized inversion for fault 1057 rupture behaviour: application to the 1984 Morgan 1058 Hill, California, earthquake. J Geophys Res 93:6275- 1059 6296

Boore D, Joyner W (1978) The influence of rupture inco- 1061 herence on seismic directivity. Bull Seismol Soc Am 1062 68:283-300

1063

Brüstle W, Müller G (1987) Stopping phases in seismo- 1064 grams and the spatiotemporal extent of earthquakes. 1065 Bull Seismol Soc Am 1:47-68 1066

Caldeira B, Bezzeghoud M, Borges JF (2009) DIRDOP: 1067 a directivity approach to determining the seismic rup- 1068 ture velocity vector. J Seismol 14:565-600. doi:10.1007/ 1069 s10950-009-9183-x 1070

Cassidy JF (1995) Rupture directivity and slip distrib- 1071 ution for the Ms 6.8 earthquake of 6 April 1992, 1072 Offshore British Columbia: an application of the em- 1073 pirical Green's function method using surface waves. 1074 Bull Seismol Soc Am 85:736-746 1075

Cesca S, Heimann S, Stammler K, Dahm T (2010) Auto- 1076 mated procedure for point and kinematic source inver- 1077 sion at regional distances. J Geophys Res 115:B06304. 1078 doi:10.1029/2009JB006450 1079

Chouliaras G (2009) Seismicity anomalies prior to 8 June 1080 2008, Mw 6.4 earthquake in Western Greece. Nat 1081 Hazards Earth Syst Sci 9:327-335 1082

Dahm T, Krüger F (1999) Higher-degree moment ten- 1083 sor inversion using far-field broad-band recordings: 1084 theory and evaluation of the method with application 1085 to the 1994 Bolivia deep earthquake. Geophys J Int 1086 137:35-50

1087

Dahm T, Kruger F, Stammler K, Klinge K, Kind R, 1088 Wylegalla K, Grasso JR (2007) The 2004 Mw 4.41089 Rotenburg, Northern Germany, Earthquake and its 1090 possible relationship with Gas Recovery. Bull Seismol 1091 Soc Am 97:691-704 1092

Dreger D, Kaverina A (2000) Seismic remote sensing 1093 for the earthquake source process and near-source 1094 strong shaking: a case study of the October 16, 19991095 Hector mine earthquake. Geophys Res Lett 27:1941- 1096 1944

1097

Dziewonski AM, Anderson DL (1981) Preliminary refer- 1098 ence earth model. Phys Earth Planet Int 25:297-356 1099

Eshghi S, Zare M (2003) Reconnaisance report on 261100 December 2003 Bam earthquake. International Insti- 1101 tute of Earthquake Engineering (IIEES) 1102

Gallovic F, Zahradnik J, Krizova D, Plicka V, Sokos 1103 E, Serpetsidaki A, Tselentis GA (2009) From earth- 1104 quake centroid to spatial-temporal rupture evolution: 1105 Mw 6.3 Movri Mountain earthquake, June 8, 2008, 1106 Greece. Geophys Res Lett 36:L21310. doi:10.1029/ 1107 2009GL040283 1108

Ganas A, Serpelloni E, Drakatos G, Kolligri M, Adamis I, 1109 Tsimi C, Batsi E (2009) The Mw 6.4 SW-Achaia (west- 1110 ern Greece) earthquake of 8 June 2008: seismological, 1111 field, GPS, observations and stress modeling. J Earthq 1112 Eng 8:1101-1124

Hartzell SH (1978) Earthquake aftershocks as Green's 1114 functions. Geophys Res Lett 5:1-4 
1116 Hartzell S, Heaton DV (1983) Inversion of strong ground 1117

1118

1119

1120

1121

1122

1123

1124

1125

1126

1127

1128

1129

1130

1131

1132

1133

1134

1135

1136

1137

1138

1139

1140 1141 Li Y, Toksöz MN (1993) Study of the source process of
1142 the 1992 Columbia Ms $=7.3$ earthquake with the em-

1142

1143

1144

1145

1146

1147

1148

1149

1150

1151

1152

1153

1154

1155

1156

1157

1158

1159

1160 Nadim F, Moghtaderi-Zadeh M, Lindholm C, Andresen

1161 A, Remseth S, Bolourchi MJ, Mokhtari M, Tvedt T

1162 (2004) The Bam earthquake of 26 December 2003.

1163 Bull Earthquake Eng 2:119-153

1164 Nielsen S, Madariaga R (2003) On the self-healing fracture

1165

1166

1167

1168 rupture history of the 1979 Imperial Valley, California, earthquake. Bull Seismol Soc Am 83:1553-1583

Hartzell S, Helmberger DV (1982) Strong-motion modelling of the Imperial Valley earthquake of 1979. Bull Seismol Soc Am 72:571-596

Haskell NA (1964) Total energy and energy spectral density of elastic wave radiation from propagating faults. Bull Seismol Soc Am 54:1811-1841

Heimann S (2010) A robust method to estimate kinematic earthquake source parameters. PhD Thesis, University of Hamburg, Germany, pp 145

Imanishi K, Takeo M (1998) Estimates of fault dimensions for small earthquakes using stopping phases. Geophys 25:2897-2900 analyze rupture process of small earthquakes using stopping phases. J Geophys Res 107:ESE2.1-ESE2.16. doi:10.1029/2001JB000201

Kostantinou KI, Melis NS, Lee SJ, Evangelidis CP, Boukouras K (2009) Rupture process and aftershock relocation of the 8 June $2008 \mathrm{Mw} 6.4$ earthquake in Northwest Peloponnese, Western Greece. Bull pirical Green's function method. Geophys Res Lett 20:1087-1090

Madariaga R (1977) High-frequency radiation from crack (stress drop) models of earthquake faulting. Geophys J R Astron Soc 51:625-651

Madariaga R (1983) High-frequency radiation from dynamic earthquake fault models. Ann Geophys 1:17-23

McGuire JJ, Zhao L, Jordan TH (2001) Teleseismic inversion for the second-degree moments of earthquake space-time distributions. Geophys J Int 145:661678

McGuire JJ, Zhao L, Jordan TH (2002) Predominance of unilateral rupture for a global catalog of large earthquakes. Bull Seismol Soc Am 92:3309-3317

Müller CS (1985) Source pulse enhancement by deconvolution of empirical Green's functions. Geophys Res Lett $12: 33-36$

mode. Bull Seismol Soc Am 93:2375-2388

Olson AJ, Apsel RJ (1982) Finite faults and inverse theory with applications to the 1979 Imperial Valley earthquake. Bull Seismol Soc Am 72:1969-2001
Pro C, Buforn E, Udías A (2007) Rupture length and 1169 velocity for earthquakes in the Mid-Atlantic Ridge 1170 from directivity effects in body and surface waves. 1171 Tectonophysics 433:65-79 1172

Roumelioti Z, Benetatos C, Kiratzi A (2009) the 141173 February 2008 earthquake (M6.7) sequence offshore 1174 south Peloponnese (Greece): source models of the 1175 three strongest events. Tectonophysics 471:272-284 1176

Selby N, Eshun E, Patton H, Douglas A (2005) Un- 1177 usual long-period Rayleigh wave from a vertical dip- 1178 slip source: the 7 May 2001, North Sea earthquake. 1179 J Geophys Res 110:B10304. doi:10.1029/2005JB003721 1180

Sokos E, Serpetsidaki A, Tselentis GA, Zahradnik J (2008) 1181 Quick assessment of the fault plane, for the recent 1182 strike-slip event in the North-Western Peloponnese, 1183 Greece, (8 June 2008, Mw 6.3). EMSC-CSEM Report 1184

Spudich P, Frazer LN (1984) Use of ray theory to calcu- 1185 late high-frequency radiation from earthquake sources 1186 having spatially variable rupture velocity and stress 1187 drop. Bull Seismol Soc Am 74:2061-2082 1188

Underhill JR (1999) Late Cenozoic deformation of the 1189 Hellenide forelands, Western Greece. Geol Soc Am 1190 Bull 101:613-634

1191

Vallée M (2007) Rupture properties of the giant suma- 1192 tra earthquake imaged by empirical Green's function 1193 analysis. Bull Seismol Soc Am 97:103-114 1194

Vallée M, Bouchon M (2004) Imaging coseismic rupture in 1195 the far field by slip patches. Geophys J Int 156:615-630 1196

Velasco AA, Ammon CJ, Lay T (1994) Empirical green 1197 function deconvolution of broadband surface waves: 1198 Rupture directivity of the 1992 Landers, California 1199 $(\mathrm{Mw}=7.3)$, earthquake. Bull Seismol Soc Am 84:735- 1200 750

1201

Velasco AA, Ammon CJ, Farrell J, Pankow K (2004) 1202 Rupture directivity of the 3 November 2002 denali 1203 fault earthquake determined from surface waves. Bull 1204 Seismol Soc Am 94:293-299

Warren LM, Shearer PM (2006) Systematic determination 1206 of earthquake rupture directivity and fault planes from 1207 analysis of long-period P-wave spectra. Geophys J Int 1208 164:46-62

1209

Wells DL, Coppersmith KJ (1994) New empirical relations 1210 among magnitude, rupture length, rupture width, rup- 1211 ture area and surface displacements. Bull Seismol Soc 1212 Am 84:974-1002

1213

Wessel P, Smith WHF (1998) New improved version of 1214 the generic mapping tools released. Eos Trans AGU 1215 79:579

1216

Zahradnik J, Gallovic F, Sokos E, Serpetsidaki A, 1217 Tselentis GA (2008) Quick fault-plane identification 1218 by geometrical method: application to Mw 6.2 Leoni- 1219 dio earthquake, January 6, 2008, Greece. Seismol Res 1220 Lett 79:653-662 


\section{AUTHOR QUERY}

NO QUERY 